irregular gout which may be read with profit.

The book will usefully serve the purpose for which it was written.

\section{WHITLA'S DICTIONARY OF TREATMENT.}

Including medical and surgical therapeutics, eighth edition.

By R. S. Allison, M.D., M.R.C.P., and C. A. Calvert, M.B., B.Ch., F.R.C.S.I. Baillière, Tindall \& Cox. London. 1938. Price 30/.

This well-known text-book originally written by the late Sir William Whitla, has now been re-written by members of the Belfast School of Medicine. It covers the whole field of medical and surgical treatment as in the original volume, and it is indeed a matter of some surprise and certainly congratulation that the field has been covered so adequately.

It is naturally impossible in considering a book which covers so wide a field to mention individual contributions, but the section dealing with chronic rheumatism and phthisis are particularly well written and comprehensive, and the section that deals with affections of the pituitary gland is also good. To show how thoroughly the book has been written, there is a paragraph in small type dealing with the gonadotropic hormone as also with the growth hormone, and mention is made of the effect of the pituitary on the thyroid through its thyrotropic principle. Mention is even made of the fact that hypophosectomy prevents diabetes mellitus in depancreatised dogs, a fact which was only discovered experimentally in 1931 and has only been applied to practical medicine very recently.

The authors have successfully carried their plan of action into effect but it seems doubtful in the present state of medicine whether it is wise to try and do so much in so little space. However, the book is only intended for reference where the relative values of various treatments are in doubt, and as this purpose is adequately fulfilled, it would be ungracious to elaborate the point, and of all the books on treatment-and they are many-this appears to be one of the very best.

\section{EVOLUTION OF OBSTETRIC ANALGESIA.}

By ANDrew M. Claye, M.D., F.R.C.S., F.C.O.G. Oxford Medical Publications. 1939. Price 6/-.

I have read, with great pleasure, Professor A. M. Claye's book on the " Evolution of Obstetric Analgesia." It is a small but excellent book in which Professor Claye deals briefly but very thoroughly with the subject.

I can recommend it strongly to all who are interested in the subject of analgesia in labour.

\section{CONTROL OF CONCEPTION.}

\section{(Second Edition.)}

By DR. R. L. Dickinson. Baillière, Tindall \& Cox. London. 1938. Price $16 \mathrm{~s}$.

Dr. Dickinson published his first text-book on this subject in joint authorship with Dr. Louise Bryant in 1931. Since then such a large amount of work has been done that a new edition became necessary, and this volume was issued in 1938.

Everyone who knows anything of contraception, honours Dr. Dickinson for his outstanding work in this field, he has given continuous attention to the subject from its earliest days and his prestige and professional standing have been of the greatest possible help to the birth control movement in America. The present publication is a textbook of 390 pages written strictly for medical practitioners and medical students and not for the general public. Its contents cover the anatomy, physiology and chemistry concerned in the subject, exhaustive descriptions of every known method of contraception, a useful chapter on methods of therapeutic abortion, details of equipment for birth control clinics, and a programme for future research.

The bibliography alone makes the book worth possessing. Eighteen pages of small type describe works in English, German and French. In each case the exact page references are given as well as names of publishers, journals and dates of publication. A feature of the book is the illustrations; there are 128 pages of fine drawings all executed by Dr. Dickinson himself. American text-books seem to be ahead of 